\title{
Responses of harbour porpoises to pile driving at the Horns Rev II offshore wind farm in the Danish North Sea
}

\author{
Miriam J. Brandt ${ }^{1, *}$, Ansgar Diederichs ${ }^{1}$, Klaus Betke $^{2}$, Georg Nehls ${ }^{1}$ \\ ${ }^{1}$ BioConsult SH, Brinckmannstrasse 31, 25813 Husum, Germany \\ ${ }^{2}$ Institut für technische und angewandte Physik GmbH, Marie-Curie-Strasse 8, 26129 Oldenburg, Germany
}

\begin{abstract}
Pile driving during offshore windfarm construction goes along with considerable noise emissions that potentially harm marine mammals in the vicinity and may cause large scale disturbances. Information on the scale of such disturbances is limited. Therefore, assessment and evaluation of the effects of offshore construction on marine mammals is difficult. During summer 2008, 91 monopile foundations were driven into the seabed during construction of the offshore wind farm Horns Rev II in the Danish North Sea. We investigated the spatial and temporal scale of behavioural responses of harbour porpoises Phocoena phocoena to construction noise using passive acoustic monitoring devices (T-PODs) deployed in a gradient sampling design. Porpoise acoustic activity was reduced by $100 \%$ during $1 \mathrm{~h}$ after pile driving and stayed below normal levels for 24 to $72 \mathrm{~h}$ at a distance of $2.6 \mathrm{~km}$ from the construction site. This period gradually decreased with increasing distance. A negative effect was detectable out to a mean distance of $17.8 \mathrm{~km}$. At $22 \mathrm{~km}$ it was no longer apparent, instead, porpoise activity temporarily increased. Out to a distance of $4.7 \mathrm{~km}$, the recovery time was longer than most pauses between pile driving events. Consequently, porpoise activity and possibly abundance were reduced over the entire 5 mo construction period. The behavioural response of harbour porpoises to pile driving lasted much longer than previously reported. This information should be considered when planning future wind farm construction.
\end{abstract}

KEY WORDS: Phocoena phocoena - Offshore windfarm - Acoustic monitoring - Behaviour · Porpoise detectors · Construction noise - Marine mammals · Acoustic activity

\section{INTRODUCTION}

It is of vital interest for science and nature conservation to understand the ecological consequences of human use of marine habitats. Virtually all human activities at sea lead to the generation of underwater noise, which may propagate over large distances. It is well documented that noise levels in the world's oceans are increasing with expanding human activities (Andrew et al. 2002, McDonald et al. 2006). High noise levels are of special concern for cetaceans, which depend on sound as the most important source of information about their environment (Richardson et al. 1995, No- wacek et al. 2007, Southall et al. 2007, Weilgart 2007, Tyack, 2008). A growing demand for sustainable and 'environmentally friendly' energy has led a growing number of countries to explore options for the installation of offshore wind farms. However, such developments may have at least temporary negative effects on the surrounding marine environment. In particular, noise emissions during the construction phase, when steel foundations may be driven into the sea floor, can cause temporary avoidance of the area by marine mammals and at close range have the potential to inflict physical damage to their sensory system (Madsen et al. 2006, Thomsen et al. 2006, Southall et al. 2007). 
In the North Sea, the harbour porpoise Phocoena phocoena is the most abundant marine mammal and is found in all coastal and offshore waters (Reid et al. 2003). The species is listed in Annexes II and IV of the EU Habitats Directive, and deliberate killing or significant disturbance of individuals are prohibited. However, given the wide distribution of harbour porpoises in this region and the numerous wind farms, both planned and in place, it is inevitable that such developments will affect harbour porpoise habitat to some extent. In order to assess the effects of offshore windfarms on harbour porpoises, knowledge of the behaviour of the species in relation to noise levels created by offshore pile driving is essential. The main aim of this study was to describe the temporal and spatial extent of disturbance and thereby assess the spatial and temporal scale at which habitat exclusion occurs.

To our knowledge, the only published studies addressing behavioural reactions of harbour porpoises to pile driving so far were carried out by Carstensen et al. (2006), Tougaard et al. (2009) and Thompson et al. (2010). All studies used static acoustic monitoring devices (T-PODs), which allow continuous recordings of harbour porpoise echolocation activities and were deployed according to a Before After Control Impact (BACI) design aimed primarily at comparing porpoise activity during the construction period to a preconstruction and/or post-construction period. Tougaard et al. (2009) studied harbour porpoise responses to pile driving during construction of the Offshore Windfarm Horns Rev I in the Danish North Sea. This study described a clear effect of pile driving on the acoustic activity of harbour porpoises up to a distance of $20 \mathrm{~km}$, with the mean time between 2 consecutive porpoise acoustic encounters (all porpoise recordings being separated by $<10 \mathrm{~min}$ ) increasing from $5.9 \mathrm{~h}$ to $7.5 \mathrm{~h}$ after pile driving. However, when comparing the affected area with a reference area, no difference in the duration of this effect was detectable. The range of the effect could therefore not be determined and the very short duration of the measured effect apparently contradicts the great distance over which it occurred. Carstensen et al. (2006) studied harbour porpoise responses during construction of the Nysted offshore windfarm in the Danish Baltic Sea. They found a longer effect, with times between porpoise encounters increasing from the normal $10-20 \mathrm{~h}$ to $35-50 \mathrm{~h}$ after construction near the windfarm, whilst a somewhat smaller effect was found in an area at a distance of about $15 \mathrm{~km}$. More recently, Thompson et al. (2010) published a study assessing the effects on cetaceans during construction of 2 wind turbines off northeast Scotland. While they found some evidence that the time between consecutive porpoise detections was longer after pile driving than randomly expected in the affected area, small sample size and high variability between areas did not allow firm conclusions or statements about the duration or scale of the effect. They concluded that while passive acoustic monitoring is a useful method to assess such effects from offshore construction work on cetaceans, a gradient sampling design would offer a more promising approach than a BACI design. Here we present such a study, using a gradient sampling design where T-PODs were deployed along a transect line reaching from the pile driving site to a maximum distance of $22 \mathrm{~km}$ in the Danish North Sea. This design was adopted to specifically test the spatial and temporal scale of the effects of windfarm construction on harbour porpoises.

The area west of Jutland and Sylt has been identified as a location with high porpoise numbers especially during the summer months (Hammond 2006, Gilles at al. 2009). It might therefore be of high importance for harbour porpoises as a breeding and nursery ground. The offshore windfarm Horns Rev II, the largest offshore construction of its time, was constructed within this area in relatively shallow waters (Fig.1), at a time of year when porpoise numbers are expected to be especially high. This provided us with the opportunity to test how pile driving in particular affects harbour porpoises in a high density area.

\section{MATERIALS AND METHODS}

Study area. The offshore windfarm Horns Rev II was erected north-west of the reef Horns Rev, which extends from the westernmost point of the Danish west coast at Blåvands Huk out $\sim 40 \mathrm{~km}$ to the west. The reef consists of an inner and outer reef separated by the Slugen Channel (Fig. 1). The windfarm, consisting of a transformer platform and 92 2.3 MW wind turbines arranged in 7 rows in a semicircular formation, is located at the northwestern part of the reef, $\sim 35 \mathrm{~km}$ west of Blåvands Huk (Fig. 1). It covers an area of $\sim 35 \mathrm{~km}^{2}$ with a water depth between 4 and $14 \mathrm{~m}$. The top seabed layer in the windfarm area consists of predominantly medium-coarse grained sand without macrophytes.

Wind turbines were erected between 19 May and 9 October 2008 on monopile foundations. The piles had a diameter of $3.9 \mathrm{~m}$, were 30 to $40 \mathrm{~m}$ long, had a wall thickness of 25 to $88 \mathrm{~mm}$, weighed 170 to $210 \mathrm{t}$, and were driven into the seabed to depths of 20 to $25 \mathrm{~m}$. The construction was performed with the aid of the jack-up barge 'Sea Jack' (A2SEA). An IHC S1200 hydraulic hammer (IHC Hydrohammer) was used for all monopiles. The maximum applied blow energy was $\sim 900 \mathrm{~kJ}$ per strike. A short ramp-up procedure with a duration of about 5 min was observed 


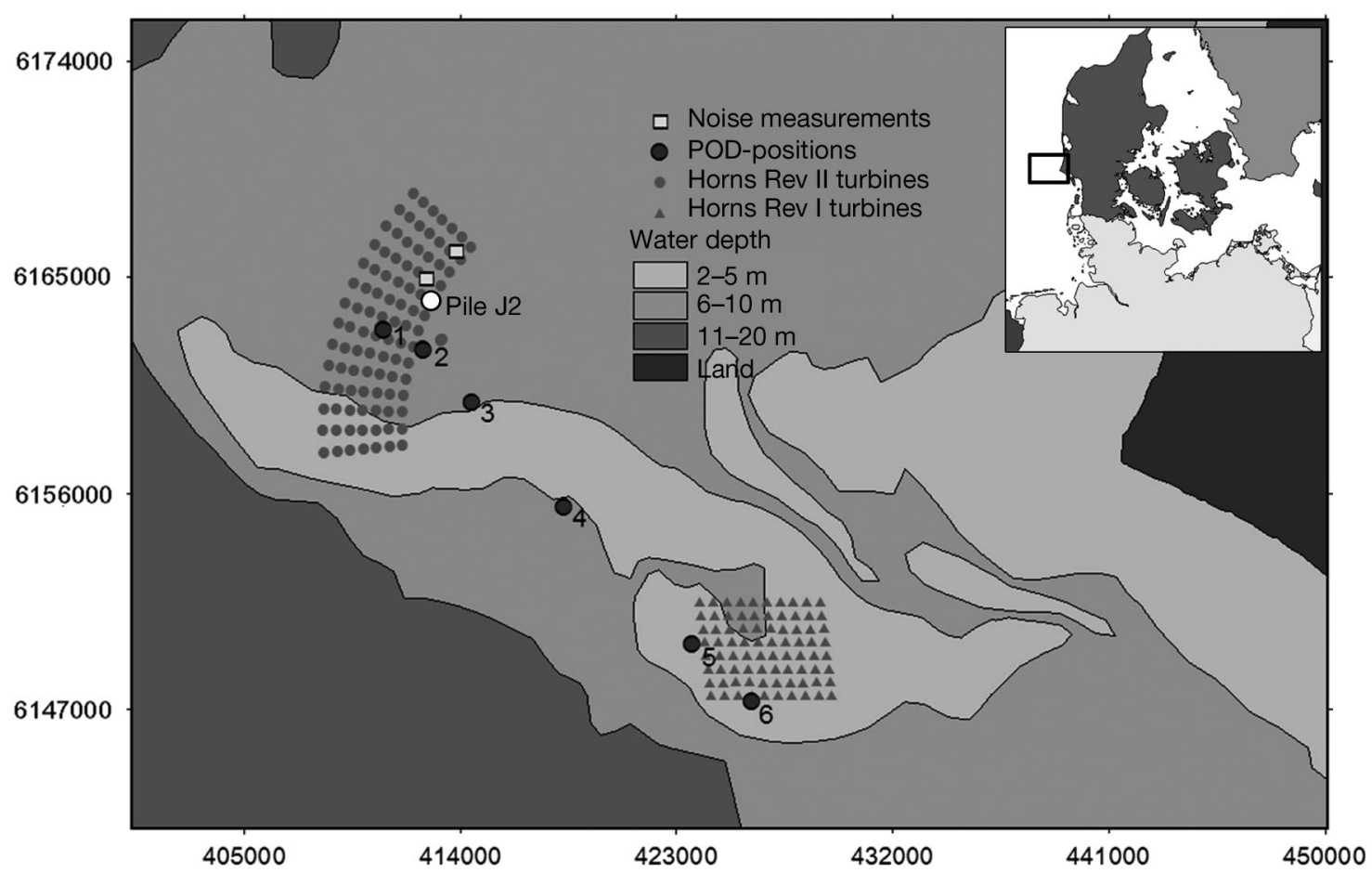

Fig. 1. Study area. Positions of the wind turbines of the windfarm Horns Rev II, where pile driving took place during this study $(\bullet)$, and the windfarm Horns Rev I $(\Delta)$ that was already installed. 01 to $6=$ positions of the T-PODs. $\square=$ positions where noise measurements were conducted during pile driving of monopile J2 (O). Grid reference system is UTM $32 \mathrm{~N}$

during noise measurements. Over this period, the blow rate was slowly increased from about 1 blow $\min ^{-1}$ to 1 blow s${ }^{-1}$. No particular plan for ramp-up procedures existed.

Noise measurements. Noise measurements were conducted on 7 September 2008 at 2 measurement points, during installation of 1 monopile (J2). An autonomous recording buoy was deployed at $720 \mathrm{~m}$ distance from the pile with a hydrophone $1.5 \mathrm{~m}$ above the sea floor. Water depth at this position was 10 to $12 \mathrm{~m}$. The system was fitted with an ITC-1001 hydrophone (International Transducer Corp.) with a recorder PMD 670 (Marantz). Recording bandwidth was $15 \mathrm{~Hz}$ to $20 \mathrm{kHz}$. Manual recordings were made aboard a ship at $2300 \mathrm{~m}$ distance from the pile using a 8105 hydrophone (Brüel \& Kjær) and a HD-P2 recorder (Tascam). The bandwidth of this system was 10 to $40 \mathrm{kHz}$. The hydrophone was deployed 7 to $8 \mathrm{~m}$ below the sea surface. At both positions, the noise was recorded in uncompressed 16 bit wave file format. These data were later evaluated with MATLAB programs. Peak level $\mathrm{L}_{\text {peak, }}$ equivalent continuous sound level $\mathrm{L}_{\mathrm{eq}}$ and average single-stroke sound exposure levels (SEL) were computed for the whole pile driving operation in consecutive intervals of $30 \mathrm{~s}$. The peak level was derived directly from the recorded time series as follows:

$$
\mathrm{L}_{\text {peak }}=20 \log \left(\left|\mathrm{p}_{\text {peak }}\right| / \mathrm{p}_{0}\right)
$$

where $p_{\text {peak }}$ is the highest positive or negative observed sound pressure in the observation interval and $\mathrm{p}_{0}$ is the reference sound pressure, which is $1 \mu \mathrm{Pa}$. $\mathrm{L}_{\mathrm{eq}}$ and SEL were computed from one-third octave spectral analyses based on Fast Fourier Transform (FFT). A single FFT with rectangular window was performed on each whole interval. FFT length was the next highest power of 2 , with reference to the number of data points, and the rest of the FFT field was filled up with zeros. For a sampling frequency of e.g. $44.1 \mathrm{kHz}$, as used in the recording buoy, the number of FFT points was thus 2097 152. The amplitude correction for this procedure ( 0 to $3 \mathrm{~dB}$ ) was applied after conversion of the FFT result to the power domain. One-third octave spectrum was then computed by summing the FFT spectral lines for each one-third octave band. Hence each of these spectra represented the $\mathrm{L}_{\text {eq }}$ for the particular $30 \mathrm{~s}$ interval. The SEL was computed from the $\mathrm{L}_{\mathrm{eq}}$ according to

$$
\mathrm{SEL}=\mathrm{L}_{\mathrm{eq}}-10 \log \left(\mathrm{n} \mathrm{T}_{0} / \mathrm{T}\right)
$$

where $\mathrm{n}$ is the number of pile driver blows within the observation interval $\mathrm{T}=30 \mathrm{~s}$, and $\mathrm{T}_{0}=1 \mathrm{~s}$.

M-weighted cumulative SELs were computed following Southall et al. (2007). Frequency weighting is a sound engineering method for deriving a single- 
number level value that accounts for the frequencydependent sensitivity of the auditory system. For highfrequency cetaceans, Southall et al. (2007) suggest an M-weighting curve with corner frequencies of $200 \mathrm{~Hz}$ and $180 \mathrm{kHz}$. Below and above these frequencies, the curve declines by $40 \mathrm{~dB}$ per decade whereas it is flat (i.e. no weighting) at the center frequencies.

POD settings. The responses of harbour porpoises to wind farm construction were monitored by continuous registration of echolocation clicks using T-PODs (version 4, Chelonia). A T-POD consists of a hydrophone, an amplifier, analogue electronic filters and a digital memory. They are equipped with a $128 \mathrm{MB}$ nonvolatile memory (up to 30 million clicks can be stored) and are powered by 2 bundles of six $1.5 \mathrm{~V}$ D-cell alkaline batteries. The filter settings can be set to a range of different click durations, centre and reference frequencies, signal bandwidths and signal strengths, that are characteristic for harbour porpoise echolocation clicks, in order to distinguish them from boat sonar and other sources. The T-POD is accompanied by the software package T-POD.exe (v.7.41), that uses an algorithm (train detection algorithm V3.0) to discriminate cetacean trains from other sources (for details see Verfuß et al. 2008, Bailey et al. 2010, Simon et al. 2010). We chose the following POD-settings: (1) target filter A: $130 \mathrm{kHz}$, (2) reference filter B: $90 \mathrm{kHz}$, (3) click bandwidth: 5, (4) noise adaptation switched on, and (5) scan limit for $\mathrm{N}$ of clicks logged: 240 . The sensitivity of T-PODs has been found to differ (Dähne et al. 2006, Verfuß et al. 2007). Therefore absolute sensitivities of individual T-PODs were measured in a laboratory environment in the German Oceanographic Museum in Stralsund, Germany. During this test tank calibration, the detection threshold of each T-POD was measured and the POD-specific sensitivity, selected in order to achieve a peak to peak detection threshold of $130 \mathrm{~dB}$ re $1 \mu \mathrm{Pa}$, was determined (for details see Verfuß et al. 2007). This POD-specific value was then used as the setting for T-PODs deployed in the field. The software sorts clicks into different train classifications. We only used the 2 with the highest probability of being actual harbour porpoise clicks ('CetHi' and 'CetLo'; Thomsen et al. 2005).

POD deployment. A total of 8 T-PODs were deployed at 6 positions along a transect line extending from inside the area where Horns Rev II was built (Position 1), across the reef and into the area where the windfarm Horns Rev I is located, south of the reef (Position 6) (Fig. 1, Table 1). The exact detection range of a T-POD is not accurately known. However, for version 3 T-PODs, a maximum detection distance of between 200 and $300 \mathrm{~m}$ has been described for harbour porpoises (Tougaard et al. 2006). In order to avoid detection of the same porpoise clicks at 2 neighbouring
T-POD positions during the same minute, the positions were set with a distance of 1.5 to $8 \mathrm{~km}$ between them. The distance from the POD positions to individual wind turbines ranged from 0.5 to $25 \mathrm{~km}$. Water depth at the T-POD positions was between 9 and $18 \mathrm{~m}$.

T-PODs were placed in the water column $\sim 1 \mathrm{~m}$ above the sea bottom. Each POD position was marked by an inflatable yellow buoy directly next to it and by an official yellow warning buoy at a distance of 100 to $150 \mathrm{~m}$. The inflatable buoy was attached to an anchor block, which was connected to a second anchor block, to which the T-POD was attached.

During the period 8 April to 7 September 2008, a total of 728 POD-days (no. of PODs deployed $\times$ days of deployment) were achieved. During the baseline period 8 April to 18 May 2008 before pile driving activities started, no data were recorded at Position 4 due to equipment loss. At all other locations, at least $17 \mathrm{~d}$ of recording were achieved during the baseline period. Some further data gaps occurred due to equipment loss or damage (Fig. 2). Pile driving activities took place between 19 May and 14 October 2008. There was only 1 pause between pile driving events that was $>4$ d (Fig. 2), and on several occasions 2 pile driving events occurred during a single day. A pile driving event lasted on average $46 \pm 14 \mathrm{~min}$ and the median time between them was $16 \mathrm{~h}$ (range: 10-309 h). During 62 pile driving events that took place between 19 May and 07 October 2008, POD data could be recorded at 3 or more POD positions during each pile driving event (Fig. 2).

To keep the animals out of the radius where physical damage from pile driving noise might occur, a seal scarer (Lofitech) and a pinger (Aquamark 100) were deployed at the construction site on average $163 \pm$ $88 \mathrm{~min}(0-461 \mathrm{~min})$ before pile driving started, and were recovered $47 \pm 46 \mathrm{~min}(0-279 \mathrm{~min})$ after pile driving finished. Pingers have been found to deter harbour porpoises to distances of 100 to $200 \mathrm{~m}$ (Kraus 1999, Barlow \& Cameron 2003, Kastelein et al. 2006). The effects of the seal scarer on harbour porpoises are not well known. However, Olesiuk et al. (2002)

Table 1. Distances of POD positions (see Fig. 1) and duration of the effect on porpoise activity as found from GAM analyses. $\mathrm{PPM} / \mathrm{h}$ : porpoise positive minutes per hour

\begin{tabular}{|lcc|}
\hline $\begin{array}{l}\text { POD } \\
\text { position }\end{array}$ & $\begin{array}{c}\text { Mean } \\
\text { distance }(\mathrm{km})\end{array}$ & $\begin{array}{c}\text { Duration of pile driving } \\
\text { effect on PPM/h (h) }\end{array}$ \\
\hline 1 & 2.5 & $24-72$ \\
2 & 3.2 & $18-40$ \\
3 & 4.8 & $17-42$ \\
4 & 10.1 & $9-21$ \\
5 & 17.8 & $10-23$ \\
6 & 21.2 & 0 \\
\hline
\end{tabular}




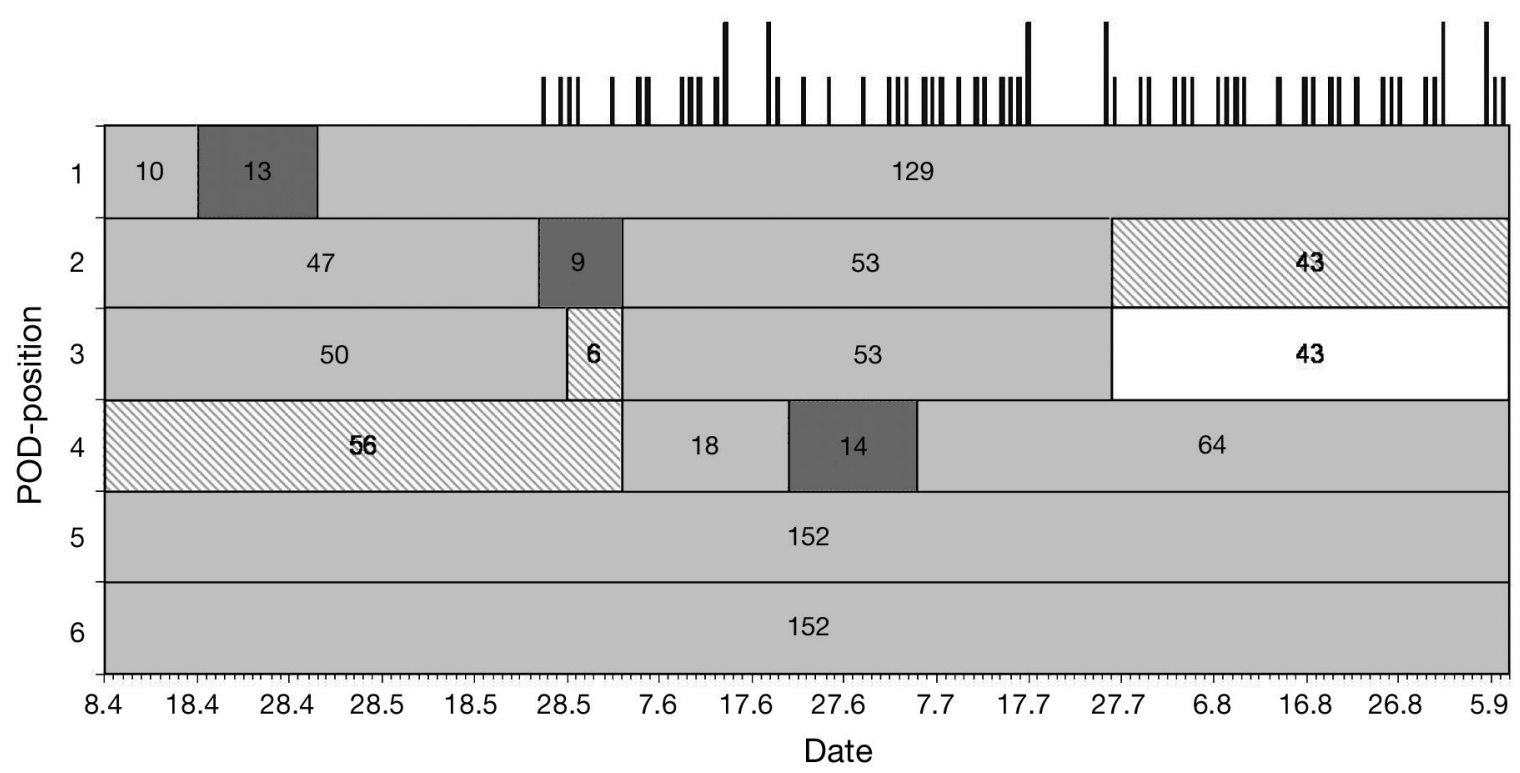

Fig. 2. Periods of T-POD deployment at the different positions (see Fig. 1). Dates given as dd.mm. Light grey bars: T-POD recorded data. Grey hatched bars: T-POD deployed but lost. Dark grey bars: T-POD deployed but did not function. White bar: no T-POD deployed. Numbers in the bars denote number of days in that period. Narrow black bars on the top of the graph show pile driving events, short bars $=1$ event, long bars $=2$ events during the same day

observed avoidance reactions by porpoises to the Airmar seal scarer, up to a distance of 2.5 to $3.5 \mathrm{~km}$ and Johnston (2002) reported a mean closest approach distance of $991 \mathrm{~m}$ during seal scarer activity compared to $364 \mathrm{~m}$ during seal scarer inactivity.

Data analysis. To determine how porpoise activity changed with respect to time after pile driving, we analysed the parameter 'porpoise positive minutes per hour' (PPM/h). This describes the number of minutes during an hour where at least 1 harbour porpoise click was recorded and can thus range from 0 to 60 . Statistical analysis was conducted using the software ' $R$ ', version 2.8.1 (www.r-project.org/).

To investigate whether there was a difference in PPM per day between the baseline period from $8 \mathrm{Apr}$ to 18 May 2008 before pile driving started and the pile driving period (19 May-7 Sept 2008), we calculated a non-parametric Mann-Whitney $U$-test for each POD position and applied Bonferroni correction on significant $p$-values to account for multiple tests on the same dataset. Only hours that were fully covered were included in the analysis.

To test for short-term effects and to determine the duration of an effect, we then proceeded by application of a Generalised Additive Model (GAM), allowing for a non-linear effect of pile driving on PPM/h, including only data from the construction period. PPM/h was chosen as the response variable and the interactions between Hour after pile driving (Hpd) and POD position, Distance to pile driving ( $\mathrm{Dpd}$, in $\mathrm{km})$ and Time of day (Time) were chosen as non linear predictor vari- ables, using standard settings for the number of knots specified. We also included Month as a factor. Because the interaction of Hpd with POD position was significant, and because we were interested to see how the duration of an effect differed with distance, we then recalculated the same model separately for each of the 6 different POD positions (PPM as response variable, Hpd, Dpd and Time as non-linear predictor variables and Month as a factor). Using the curve that the GAM fitted to the relationship between PPM/h and Hpd, we then defined the range between the point where $\mathrm{PPM} / \mathrm{h}$ reached the overall average and where it reached the first local maximum after the initial increase. This time span we report as the possible duration of the effect of pile driving on harbour porpoise behaviour.

\section{RESULTS}

\section{Noise measurements}

During construction of monopile J2, when noise measurements were conducted, 449 blows were necessary to reach the final penetration of $21 \mathrm{~m}$ according to the pile driver record file. The time from the first to the last blow was $30 \mathrm{~min}$ (04:53:30-05:23:19). At $720 \mathrm{~m}$ distance, during 1 pile driving event, the peak level reached $196 \mathrm{~dB}$ re $1 \mu \mathrm{Pa}$, the SEL level reached a max-

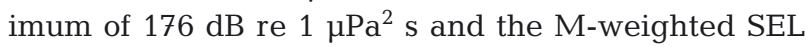
(see Southall et al. 2007) reached $170 \mathrm{~dB}$ re $1 \mu \mathrm{Pa}^{2} \mathrm{~s}$ 
(Fig. 3). At a distance of $2300 \mathrm{~m}$ to pile driving, peak levels reached $184 \mathrm{~dB}$ re $1 \mu \mathrm{Pa}$, SEL $164 \mathrm{~dB}$ re $1 \mu \mathrm{Pa}^{2} \mathrm{~s}$ and M-weighted SEL reached $157 \mathrm{~dB}$ re $1 \mu \mathrm{Pa}^{2} \mathrm{~s}$. These levels were observed at the maximum applied blow energy of $\sim 850 \mathrm{~kJ}$. From the spectrum of the pile driving noise measured at 720 and $2300 \mathrm{~m}$ distance (Fig. 4), it can be seen that the spectral maximum was found between $80 \mathrm{~Hz}$ and $200 \mathrm{~Hz}$ and noise levels decreased at the higher frequencies until at a distance of $2300 \mathrm{~m}$, background noise levels were reached at about $40000 \mathrm{~Hz}$. Fig. 5 shows the broadband sound level relative to pile driver blow energy.

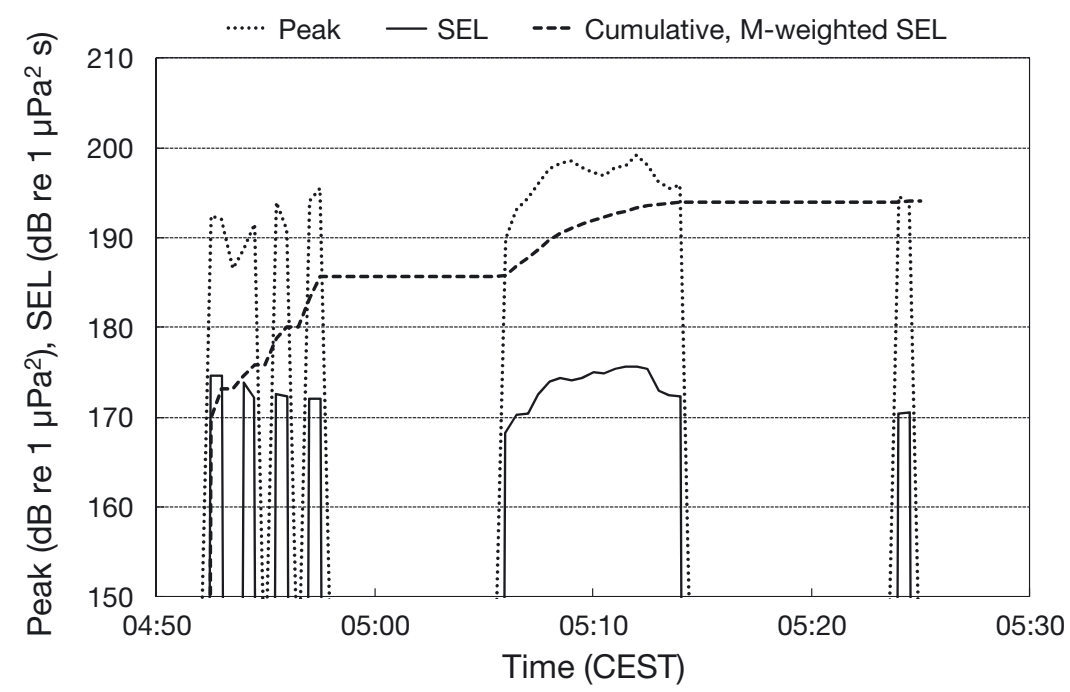

Fig. 3. Peak level and single-stroke sound exposure level (SEL) for the whole pile driving operation measured at $720 \mathrm{~m}$ distance. Also shown is the $M$-weighted cumulative SEL (the $M$ weighting function for 'HF cetaceans' was used; Southall et al. 2007). The difference between the non-cumulative unweighted and M-weighted SEL varied from $\sim 4$ to $7 \mathrm{~dB}$

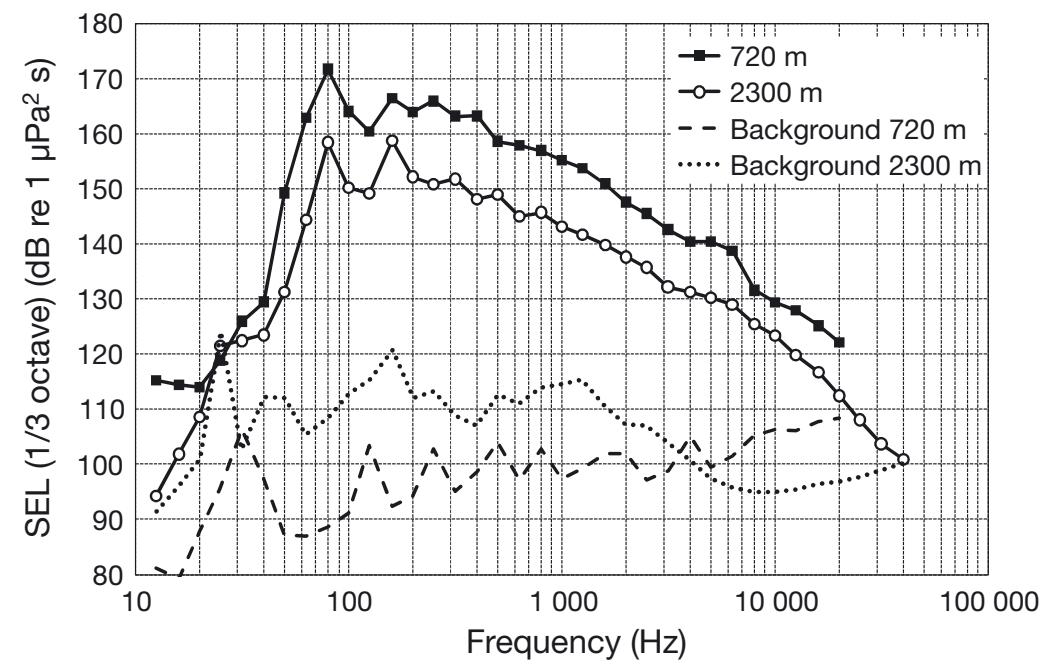

Fig. 4. Spectra of pile driving noise at the 2 measurement locations (see Fig. 1), averaged from 24, $850 \mathrm{~kJ}$ blows. SEL: single-stroke sound exposure level

\section{Porpoise activity (PPM/h)}

As revealed by non-parametric tests, porpoise activity (PPM/h) significantly decreased during the construction period (19 May-7 September 2008) as compared to the baseline period (8 April-18 May 2008) at POD-Positions $1\left(Z_{637,2555}=-7.47, \mathrm{p}<0.001\right), 2\left(Z_{949,1355}\right.$ $=-11.10, \mathrm{p}<0.001)$ and $3\left(Z_{973,1427}=-14.42, \mathrm{p}<0.001\right)$, while no significant effect was found at Positions 5 $\left(Z_{949,2579}=-0.45, \mathrm{p}=0.66\right)$ and $6\left(Z_{925,2580}=-0.87, \mathrm{p}=\right.$ 0.38) (Fig. 6). At Position 4, no baseline data were available due to equipment loss.

The GAM explained $27.9 \%$ of the overall variance in the data. It revealed significant effects of Dpd, Time and Month on PPM/h (Table 2). There was also a significant effect of the interaction of POD position with Hpd on PPM/h (Table 2). Therefore we split the analysis up for the different POD positions and again tested for the influence of Hpd on $\mathrm{PPM} / \mathrm{h}$ for each position separately while controlling for Dpd and Time and Month. Hpd, Dpd and Month had a significant effect on PPM/h at all positions, while Time only had a significant effect at some positions (Table 3). Explanatory power of the model decreased at POD positions further from the pile driving site (Table 3). The curve on the relationship between PPM/h and hour after pile driving (the parameter of main interest) that the GAM fitted to the data was of different shapes at the different POD positions. In Fig. 7, the deviation of $\mathrm{PPM} / \mathrm{h}$ from the overall mean (calculated over all available hours at a given position) and how this changes with hours after pile driving can be seen for the different positions. At Position 1, PPM/h steadily increased after the pile driving event. PPM/h was substantially below the overall mean up to $24 \mathrm{~h}$ after pile driving. However, PPM/h continued to increase with a narrow confidence interval until reaching the first local maximum at $72 \mathrm{~h}$ after pile driving. At Positions 2 and 3 , the pattern is similar: $\mathrm{PPM} / \mathrm{h}$ steeply increased after pile driving. The overall mean was reached at $18 \mathrm{~h}$ (Position 2) and at $17 \mathrm{~h}$ (Position 3) after pile driving. At $40 \mathrm{~h}$ (Position 2) and 42 hours (Position 3) after pile driving, PPM/h reached the first local maximum and then fluctuated widely around the mean. At Positions 4 and $5, \mathrm{PPM} / \mathrm{h}$ increased more steeply and at $9 \mathrm{~h}$ (Position 4) and $10 \mathrm{~h}$ (Position 5) after pile driving, the overall average was reached 


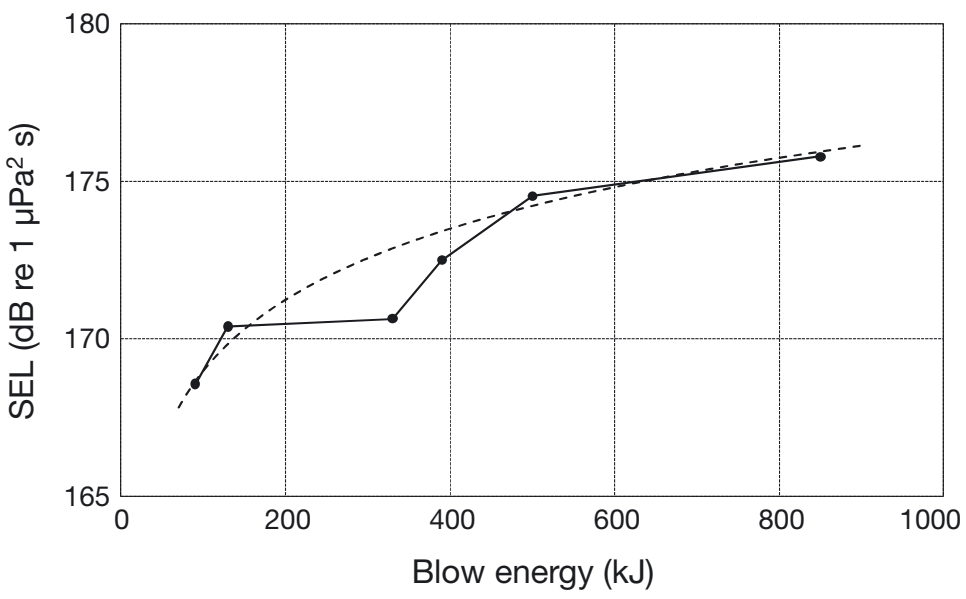

Fig. 5. Broadband sound level as a function of pile driver blow energy, observed at $720 \mathrm{~m}$ distance. The formula of the fitted dashed curve is $\mathrm{SEL}=7.5 \log (\mathrm{E})+154$. Each point represents the energetic average from between 10 and 26 blows, depending on the energy level. SEL: singlestroke sound exposure level ing sample size as in most cases the time between pile driving events was less than $50 \mathrm{~h}$. Thus, predictive power for the later periods decreased. The range of the duration of the effect of pile driving on harbour porpoises, together with the predicted sound exposure levels at the different POD positions, are given in Table 1. During the first hour after pile driving, mean porpoise activity was 0 at Positions 1 to 3, while at Positions 4 and 5 there was a reduction in porpoise activity of between $32 \%$ and $49 \%$ relative to the overall mean PPM/h value and mean PPM/h more than $70 \mathrm{~h}$ after pile driving (Table 4). At Position 6 (at a distance of $22 \mathrm{~km}$ ), PPM/h decreased by $2 \%$ compared to the overall mean, but increased by $31 \%$ relative to $\mathrm{PPM} / \mathrm{h}$ more than $70 \mathrm{~h}$ after pile driving (Table 4). substantially sooner. This increase in PPM/h also levelled off sooner at these positions $(21 \mathrm{~h}$ at Position 4 and $23 \mathrm{~h}$ at Position 5). At Position 6, the shape of the curve differed: $\mathrm{PPM} / \mathrm{h}$ was higher than the overall mean, up to about $35 \mathrm{~h}$ after pile driving, while decreasing and fluctuating around the overall mean afterwards. At all POD-positions the confidence intervals for PPM/h widened substantially when more time after pile driving elapsed. This was due to a decreas-

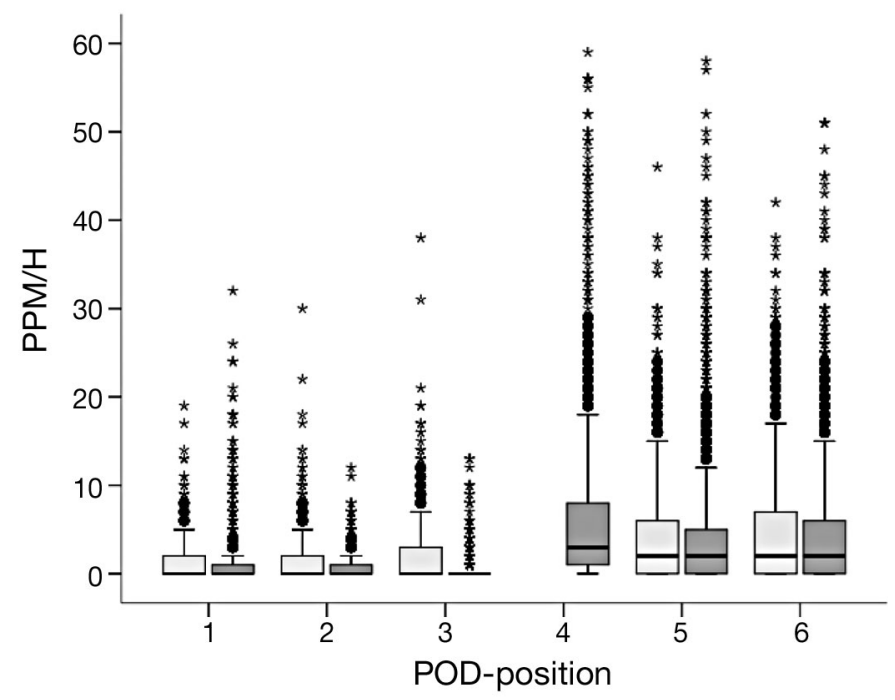

Fig. 6. Porpoise positive minutes per hour (PPM/h) during the baseline period (08 Apr-18 May 08, light bars) and the construction period (19 May -07 Sep 08, dark bars) by POD position. Dark band: mean; box: $25 \%$ quartiles; whiskers: $25 \%$ quartiles minus outliers and extremes; blobs: outliers, defined as values which are between 1.5 and 3 box lengths from either end of the box; asterisks: extremes, defined as values that are more than 3 box lengths from either end of the box

\section{DISCUSSION}

We found a clear negative effect of pile driving during wind farm construction on porpoise acoustic activity that was detectable out to a distance of $17.8 \mathrm{~km}$. At the closest distance studied $(2.5 \mathrm{~km})$, porpoise activity was reduced between 24 to $72 \mathrm{~h}$ after pile driving activity, and the duration of this effect gradually declined with distance. At the furthest distance studied $(21.2 \mathrm{~km})$, we no longer found a negative effect of pile driving on porpoise activity; instead, activity was higher than the overall average for about $30 \mathrm{~h}$ after pile driving. This might indicate that porpoises at this distance showed no behavioural reaction to pile driving. Animals moving away from the construction site might have caused porpoise abundance and thus porpoise acoustic activity to temporarily increase as animals aggregated there. The lower limit we report for the duration of the effect was based on the time when porpoise activity reached the overall average. However,

Table 2. Results from the GAM on the effects of 4 independent variables on porpoise activity (porpoise positive minutes per hour, PPM/h). F-values and estimated degrees of freedom (edf) are given; the p-value of the main effect to be tested is indicated in bold. The model explained $27.9 \%$ of the overall variance in the data

\begin{tabular}{lccc|}
\hline Independent variable & $\mathrm{F}$ & edf & $\mathrm{p}$ \\
\hline $\begin{array}{l}\text { Hour after pile driving } \\
\quad \times \text { POD position }\end{array}$ & 13.5 & 28.0 & $<\mathbf{0 . 0 0 0 1}$ \\
$\begin{array}{l}\text { Distance } \\
\text { Time of day }\end{array}$ & 195.1 & 8.9 & $<0.0001$ \\
Month & 6.9 & 8.4 & $<0.0001$ \\
& 41.3 & 4 & $<0.0001$ \\
\hline
\end{tabular}


Table 3. Results from the GAM on the effects of Hours after pile driving (Hpd), Distance to pile driving (Dpd), Time of day and Month on porpoise activity (porpoise positive minutes per hour, PPM/h). The $F$ values for all 4 parameters are given, with significance values indicated as follows: ${ }^{* * *} \mathrm{p}<0.001,{ }^{* *} \mathrm{p}<0.01,{ }^{*} \mathrm{p}<0.05, \mathrm{~ns}$ : $\mathrm{p}>0.05$

\begin{tabular}{|lcccccc|}
\hline \multirow{2}{*}{$\begin{array}{l}\text { POD } \\
\text { position }\end{array}$} & \multirow{2}{*}{$\begin{array}{c}\text { Mean Dpd } \\
(\mathrm{km})\end{array}$} & Hpd & Dpd & Time & Month & Variance \\
\cline { 3 - 6 } & explained (\%) & \\
\hline 1 & 2.6 & $56.2^{* * *}$ & $10.4^{* * *}$ & $2.3^{*}$ & $39.2^{* * *}$ & 24.7 \\
2 & 3.2 & $15.9^{* * *}$ & $4.5^{* * *}$ & 0.8 ns & $12.0^{* * *}$ & 15.0 \\
3 & 4.8 & $15.8^{* * *}$ & $4.9^{* * *}$ & 0.4 ns & $7.7^{* * *}$ & 13.5 \\
4 & 10.1 & $4.6^{* * *}$ & $12.8^{* * *}$ & $3.2^{* *}$ & $40.6^{* * *}$ & 18.8 \\
5 & 17.8 & $7.2^{* * *}$ & $5.1^{* * *}$ & $5.1^{* * *}$ & $42.2^{* * *}$ & 14.2 \\
6 & 21.7 & $5.7^{* * *}$ & $4.3^{* * *}$ & $9.3^{* * *}$ & $26.7^{* * *}$ & 9.6 \\
\hline
\end{tabular}

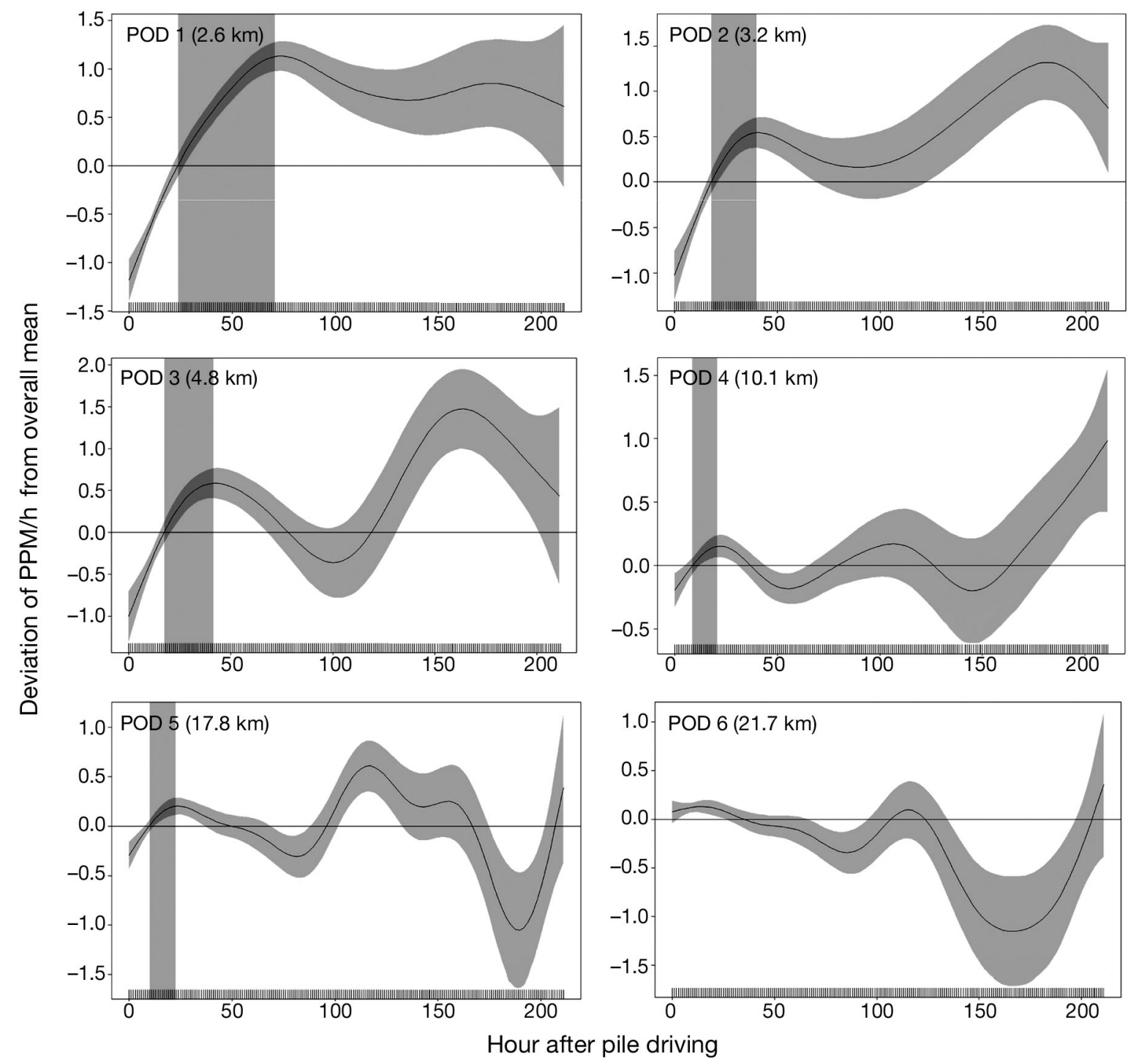

Fig. 7. Relationship between porpoise positive minutes per hour (PPM/h) and Hour after pile driving (Hpd) as fitted by the GAM. The graphs show the deviance of PPM/h from the overall mean (depicted as the horizontal line) by Hpd at each of the 6 POD positions. Grey shaded areas represent $95 \%$ confidence intervals. Grey shaded vertical boxes indicate the area that is reported as the range of the possible duration of the effect 
Table 4. Mean porpoise activity (porpoise positive minutes per hour, PPM/h) in the first hour after pile driving (Hpd), overall means and means for all hours $>70 \mathrm{Hpd}$, for each POD position. Sample sizes are given in brackets. The change in PPM/h during the hour after pile driving relative to the other 2 means is also shown

\begin{tabular}{|lcccc|}
\hline $\begin{array}{l}\text { POD } \\
\text { position }\end{array}$ & $1 \mathrm{Hpd}$ & $\begin{array}{c}\text { Mean PPM/h } \\
\text { Overall }\end{array}$ & $>70 \mathrm{Hpd}$ & $\begin{array}{c}\text { Change } \\
(\%)\end{array}$ \\
\cline { 2 - 4 } 1 & $0.0(70)$ & $0.9(3192)$ & $1.8(356)$ & -100 \\
2 & $0.0(36)$ & $1.0(2304)$ & $1.0(207)$ & -100 \\
3 & $0.0(37)$ & $1.1(2400)$ & $0.6(232)$ & -100 \\
4 & $3.9(51)$ & $6.2(1896)$ & $5.7(328)$ & -32 to -37 \\
5 & $2.9(70)$ & $4.3(3528)$ & $5.7(356)$ & -33 to -49 \\
6 & $4.6(54)$ & $4.7(3505)$ & $3.5(356)$ & -2 to +31 \\
\hline
\end{tabular}

tion site in the North Sea, where the same seal scarer model was used, the signal from the seal scarer was not found to be louder than that of pile driving at $14 \mathrm{kHz}$ (Betke \& Matuschek 2010). An effect of the seal scarer on porpoise activity would thus not be expected to reach as far as $18 \mathrm{~km}$. Nevertheless, porpoise responses to pile driving, especially at close distances, are confounded by the use of scaring devices. However, as pile driving during windfarm construction in European waters always involves the deployment of pingers and seal scarers, the inability to differentiate

the overall average includes data that are influenced by pile driving, so it cannot be seen as a 'normal' baseline value for the construction period, especially where the effects of pile driving were long lasting. As it was not possible to determine an exact baseline (due to the short time interval between pile driving events), we chose to report a range of effect duration based on mean and first maximum activity levels as the best available estimate of baseline activity during the construction period. Due to the biased average, however, the reported upper limit of the effect duration is more likely than the lower limit. It becomes clear from increasing confidence intervals in the graphs that with more time elapsing after pile driving, predictive power of the GAM decreases. This is caused by a substantial decrease in sample size, as only a few pile driving events were $>50 \mathrm{~h}$ apart.

Another additional factor that may contribute to a comparably long-lasting effect in the immediate vicinity to the pile driving location could be increased shipping activity that continues for some time after pile driving is finished. However, this noise is unlikely to have caused effects at distances of up to $18 \mathrm{~km}$. A further confounding factor is that porpoise behaviour may have changed due to the deployment of the scaring devices. Considering the scale of the observed effect, this seems unlikely. Pingers have been found to deter harbour porpoises to distances of only 100 to $200 \mathrm{~m}$ (Kraus 1999, Barlow \& Cameron 2003, Kastelein et al. 2006). Seal scarers on the other hand were found to deter porpoises up to a distance of between 1 and $3.5 \mathrm{~km}$ (Olesiuk et al. 2002, Johnston 2002). The source level of the Lofitech seal scarer as reported by the manufactures is $189 \mathrm{~dB}$ re $1 \mu \mathrm{Pa}$ peak whereas pile driving is considerably louder. However, the main energy of the seal scarer signal is at higher frequencies (about $14 \mathrm{kHz}$ ) than that of pile driving. Porpoises may be more sensitive to noise at those higher frequencies because their hearing threshold at $14 \mathrm{kHz}$ is at least $40 \mathrm{~dB}$ lower than at $500 \mathrm{~Hz}$ (Kastelein et al. 2002). However, during measurements at another construc- these effects does not compromise conclusions about the effects of windfarm construction on harbour porpoises in Europe.

The median time between succeeding pile driving events was $16 \mathrm{~h}$, during which porpoise activity did not fully recover at a distance up to about $4.8 \mathrm{~km}$, as the effect of pile driving on PPM/h lasted longer than $16 \mathrm{~h}$ at that distance. Consequently, porpoise activity close to the pile driving site was lower than expected during the whole 5 mo of the construction period. This is indicated by a significantly lower mean value for PPM/h during the construction period as compared to PPM/h values recorded in the baseline period up to a distance of $4.8 \mathrm{~km}$ (POD position 3); while at greater distances the difference between baseline and construction period is less apparent due to a much shorter-lasting effect of pile driving on $\mathrm{PPM} / \mathrm{h}$.

The spatial scale of porpoise responses that we found are in line with the $20 \mathrm{~km}$ range that has been previously suggested (Tougaard et al. 2009, Thompson et al. 2010). However, using a gradient sampling design this study is the first to demonstrate at what distance pile driving noise no longer negatively affected porpoise activity. Furthermore, in the vicinity of the construction site, the effect demonstrated during this study lasted considerably longer than has been previously described by Carstensen et al. (2006) at Nystedt and by Tougaard et al. (2009) at Horns Rev I. Pile diameter at Horns Rev I (4 m) and thus probably source levels during pile driving were almost identical to this study at Horns Rev II, and therefore this discrepancy is surprising. However, these studies are not directly comparable because Carstensen et al. (2006), Tougaard et al. (2009) and Thompson et al. (2010) analysed the duration of waiting times between 2 consecutive porpoise encounters while we analysed PPM/h. In cases where baseline data from previous years are not available (as during this study) we find PPM/h to be a better parameter to analyse how porpoise activity is affected by pile driving, because it allows the tracking of the postpile driving increase in porpoise activity on a fine tem- 
poral scale. T-PODs during studies by Carstensen et al. (2006), Tougaard et al. (2009) and Thompson et al. (2010) were deployed according to a BACI design, whereas we used a gradient sampling design that better enables one to detect how temporal effects differ with distance.

The PPM/h variable provides relative indices of porpoise activity but cannot at present be directly translated into porpoise density. However, previous studies have found these parameters to correlate broadly with porpoise densities obtained from porpoise sightings (Tougaard et al. 2006, Siebert \& Rye 2008). So porpoise acoustic activity seems to be linked to some extent to relative changes in porpoise densities although behavioural parameters may well play a vital role here also. Considering a maximum swimming speed in harbour porpoises of about $4.3 \mathrm{~m} \mathrm{~s}^{-1}$, it is surprising that we found an instant effect of pile driving on porpoise acoustic activity at distances of $18 \mathrm{~km}$, and the same applies to results by Tougaard et al. (2009). If a decrease in acoustic activity reflected animals moving out of the affected area, one would assume a delayed decrease at greater distances because animals leaving the near vicinity have to pass PODs at greater distances. It might be argued that declining acoustic activity in the area does not reflect a decrease in density but simply a change in the animals' behaviour such that porpoises remain silent after pile driving and use their sonar less frequently. Studies on other cetacean species such as pilot whales, sperm whales and Cuvier's beaked whales indeed have documented such a response to other noise exposures (for review, see Weilgart 2007). Mostly, whales remained silent or reduced vocalising activity during noise exposure but resumed normal activity shortly after the noise stopped. Conversely, some studies have described an increase in vocalisation by pilot whales during noise exposure (Rendell \& Gordon 1999). Two studies also addressed this issue in harbour porpoises: Koschinski et al. (2003) found no significant difference in the use of echolocation by porpoises when subjected to turbine noise; Teilmann et al. (2006) found echolocation activity of harbour porpoises to decrease in 3 out of 25 sessions when various frequency sounds with a source level of $153 \mathrm{~dB}$ re $1 \mu \mathrm{Pa}$ (rms) were played back to them. Although during this study, porpoises in the vicinity of pile driving might have reduced echolocation activity as a response to the sound of pile driving, we see no convincing reason why animals that rely on their sonar for orientation and foraging should cease doing so for over $20 \mathrm{~h}$ after pile driving noise stopped. We think that the decrease in acoustic activity is the result of a combined effect on porpoise behaviour and abundance. If animals change from foraging and resting behaviour to moving away from a noise source, this will result in a more directional movement. Considering the high directionality of the porpoise echolocation beam, this may greatly reduce the possibility of a click being recorded by the T-POD. Even if it takes some time for the animals to move out of the area, this change in behaviour will cause a direct effect on porpoise acoustic activity as recorded by T-PODs.

The difference of sound levels of about $12 \mathrm{~dB}$ measured between $720 \mathrm{~m}$ and $2300 \mathrm{~m}$ is quite high for the North Sea. A study conducted by the German Navy (Thiele \& Schellstede 1980) suggests a level decay of $\sim 8 \mathrm{~dB}$ in the major frequency range of pile driving noise over such a distance. However, the present study was located in relatively shallow water (about 4-14 m), where sound propagation is known to be highly variable and difficult to predict. As a major effect, transmission loss at low frequencies is affected by the water depth. Below a cut-off frequency, no sound propagation is possible (Jensen et al. 2000). This effect cuts off low-frequency components of the noise and can thus reduce its peak level and broadband SEL. The cut-off frequency is not only a function of water depth, but also of the impedance of the lower boundary of the propagation channel, that is, of the physical properties of the sediment. These, however, are often unknown. At $5 \mathrm{~m}$ water depth, for example, the cut-off can vary from about 80 to $300 \mathrm{~Hz}$. The spectral maximum of the pile driving noise at Horns Rev II was found to be between $80 \mathrm{~Hz}$ and $200 \mathrm{~Hz}$. As effects on porpoises depend highly upon sound propagation characteristics in the area, caution needs to be applied when trying to extrapolate our results to other areas.

To assess the effects of underwater noise on marine mammals, Southall et al. (2007) proposed a frequencyweighting procedure to take the hearing abilities of marine mammals into account, and a procedure to account for cumulative exposures. For the group of highfrequency cetaceans such as the harbour porpoise, the onset of hearing impairment, defined as a Temporary Threshold Shift (TTS), would be reached at $183 \mathrm{~dB}$ re $1 \mu \mathrm{Pa}^{2} \mathrm{~s}$ SEL and Permanent Threshold Shift (PTS) at $198 \mathrm{~dB}$ re $1 \mathrm{uPa}^{2}$ s SEL (all M-weighted) (Southall et al. 2007). During this study the cumulative M-weighted SEL level reached a maximum of $194 \mathrm{~dB}$ re $1 \mu \mathrm{Pa}^{2} \mathrm{~s}$ at $720 \mathrm{~m}$ distance. Therefore the noise level where Southall et al. (2007) predicted PTS to occur in high-frequency cetaceans was not reached at this distance. However, a

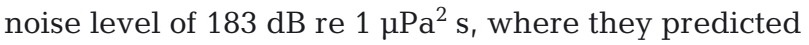
TTS to occur, was reached after about $1.5 \mathrm{~min}$. At $2300 \mathrm{~m}$ distance the cumulative $\mathrm{M}$-weighted SEL level reached a maximum of $182 \mathrm{~dB}$ re $1 \mu \mathrm{Pa}^{2} \mathrm{~s}$. This was therefore below PTS and TTS levels as predicted by Southall et al. (2007). However, recent work by Lucke et al. (2009) indicates that harbour porpoises may be more sensitive to noise exposures than was suggested by 
Southall et al. (2007) for high-frequency cetaceans. Exposing 1 individual to single airgun stimulus, they found the animal to suffer TTS at $199.7 \mathrm{~dB}_{\mathrm{pk}-\mathrm{pk}}$ re $1 \mu \mathrm{Pa}$, and a sound exposure level of $164.3 \mathrm{~dB}$ re $1 \mu^{P^{2}}{ }^{2}$ s. According to this measure, a porpoise would have suffered TTS immediately at $720 \mathrm{~m}$ and after about $2 \mathrm{~min}$ at $2300 \mathrm{~m}$ distance during this study.

With a maximum swimming speed of about $4.3 \mathrm{~m} \mathrm{~s}^{-1}$ (Otani 2000), a porpoise should be able to leave the $750 \mathrm{~m}$ radius in about $3 \mathrm{~min}$. According to both TTS criteria proposed by Southall et al. (2007) and Lucke et al. (2009) this would not be enough time for a porpoise to escape TTS. It might further be argued that animals are willing to endure potentially harmful sound levels when essential resources exist in the area. Especially in birds, many studies have shown more risk-taking behaviour when starvation risk increases (e.g. Cresswell \& Whitfield 2008), and porpoises may equally endure harmful noise if by leaving the area they face a higher risk of starvation. At present, no data on this subject are available for harbour porpoises. Limited information on the levels at which anthropogenic noise causes hearing impairment in high frequency cetaceans and the discrepancies between TTS levels published by Southall et al. (2007) and Lucke et al. (2009) show that caution is required when applying TTS and PTS criteria. However, results from noise measurements during this study clearly show that mitigation measures such as the use of bubble curtains and scaring devices are to be recommended to prevent individuals from the risk of injury from pile driving operations, and further studies into the effectiveness of these measures are needed (Nehls et al. 2007).

\section{CONCLUSIONS}

Using passive acoustic monitoring, this study revealed a marked negative influence of pile driving on the acoustic activity of harbour porpoises. At 24 to $72 \mathrm{~h}$ in close proximity to the construction site, the temporal scale of this effect lasted much longer than found in previous studies. The duration of the effect declined with increasing distance, and no negative effect was found at a mean distance of $22 \mathrm{~km}$. This information should be considered during future scheduling of pile driving activities within and between wind farms in European waters. Furthermore, sound measurements conducted during pile driving indicate that hearing impairment could potentially have occurred close to the construction site. Both the risk of hearing impairment in harbour porpoises and the far reaching disturbance effect highlight the necessity to develop suitable mitigation procedures. Here attention should especially be given to the development of measures that aim to reduce noise emission into the water.
Acknowledgements. Financial support for this study was provided by DONG Energy. We thank Christopher Honnef and the crew of the 'Tine Bødker' for their support with field work. Many thanks also go to Michael Dähne and Ursula Verfuß from the German Oceanographic Museum in Stralsund, Germany, for test-tank-calibration of the T-PODs. Special thanks go to Jakob Tougaard, Ruth Leeney and 2 anonymous referees for many helpful comments that greatly improved this manuscript.

\section{LITERATURE CITED}

Andrew RK, Howe BM, Mercer JA (2002) Ocean ambient sound: comparing the 1960 s with 1990 s for a receiver off the Californian coast. ARLO 3:65-70

Bailey H, Clay G, Coates EA, Lusseau D, Senior B, Thompson PM (2010) Using T-PODS to assess variations in the occurrence of bottlenose dolphins and harbour porpoises. Aquat Conserv 20:150-158

Barlow J, Cameron GA (2003) Field experiments show that acoustic pingers reduce marine mammal bycatch in the California drift gill net fishery. Mar Mamm Sci 19: 265-283

Betke K, Matuschek R (2010) Messungen von Unterwasserschall beim Bau der Windenergieanlagen im Offshore-Testfeld 'Alpha Ventus'. Final report for Stiftung Offshore Windenergie (available at: www.bsh.de/de/Meeresnutzung/ Wirtschaft/Windparks/StUK3/StUK3-Schall-Bauphase-15 Mar2010.pdf)

Carstensen J, Henriksen OD, Teilmann J (2006) Impacts of offshore wind farm construction on harbour porpoises: acoustic monitoring of echo-location activity using porpoise detectors (T-PODs). Mar Ecol Prog Ser 321: 295-308

Cresswell W, Whitfield DP (2008) How starvation risk in Redshanks Tringa totanus results in predation mortality from Sparrowhawks Accipiter nisus. Ibis 150:209-218

Dähne $M$, Verfuß UK, Diederichs A, Meding A, Benke H (2006) T-Pod Test Tank Calibration and Field Calibration. In: Leeney RH, Tregenza NJC (eds) Proc Workshop Static Acoustic Monitoring of Cetaceans. 20th Annual Meeting of the European Cetacean Society, Gdynia, Poland 2 April 2006. ECS newsletter No. 46 Special Issue, p 34-36,

Gilles A, Scheidat M, Siebert U (2009) Seasonal distribution of harbor porpoises and possible interference of offshore wind farms in the German North Sea. Mar Ecol Prog Ser 383:295-307

Hammond PS (2006) Small cetaceans in the European Atlantic and North Sea (SCANS-II). LIFE project number LIFE04NAT/GB/000245, final report. biology.st-andrews. ac.uk/scans2/documents/final/SCANS-II_final_report.pdf

Jensen FB, Kupermann WA, Porter MB, Schmidt H (2000) Computational Ocean Acoustics. Springer, New York, NY

Johnston DW (2002) The effect of acoustic harassment devices on harbour porpoises (Phocoena phocoena) in the Bay of Fundy, Canada. Biol Conserv 108:113-118

Kastelein RA, Bunskoek P, Hagedoorn M (2002) Audiogram of a harbour porpoise (Phocoena phocoena) measured with narrow-band frequency-modulated signals. J Acoust Soc Am 112:334-344

Kastelein RA, Jennings N, Verboom WC, Haan D, Schooneman NM (2006) Differences in the response of a striped dolphin (Stenella coeruleoalba) and a harbour porpoise (Phocoena phocoena) to an acoustic alarm. Mar Environ Res 61:373-378

Koschinski S, Culik BM, Henriksen OD, Tregenza N, Ellis G, Jansen C, Kathe G (2003) Behavioural reactions of free- 
ranging porpoises and seals to the noise of a simulated 2 MW windpower generator. Mar Ecol Prog Ser 265: $263-273$

Kraus S (1999) The once and future ping: challenges for the use of acoustic deterrents in fisheries. Mar Technol Soc J 33:90-93

Lucke K, Siebert U , Lepper PA, Blanchet MA (2009) Temporary shift in masked hearing thresholds in a harbour porpoise (Phocoena phocoena) after exposure to seismic airgun stimuli. J Acoust Soc Am 125:4060-4070

Madsen PT, Wahlberg M, Tougaard J, Lucke K, Tyack PL (2006) Wind turbine underwater noise and marine mammals: implications of current knowledge and data needs. Mar Ecol Prog Ser 309:279-295

McDonald MA, Hildebrand JA, Wiggins SM (2006) Increases in deep ocean ambient noise in the Northeast Pacific west of San Nicolas Island, California. J Acoust Soc Am 120: $711-718$

Nehls G, Betke K, Eckelmann S, Ros M (2007) Assessment and costs of potential engineering solutions for the mitigation of the impacts of underwater noise arising from the construction of offshore windfarms. BioConsult $\mathrm{SH}$, Husum, on behalf of COWRIE Ltd.

Nowacek DP, Thorne LH, Johnston MP, Tyack PL (2007) Responses of cetaceans to anthropogenic noise. Mammal Rev 37:81-115

Olesiuk PF, Nichol LM, Sowden MJ, Ford JKB (2002) Effect of the sound generated by an acoustic harassment device on the relative abundance and distribution of harbor porpoises (Phocoena phocoena) in retreat passage, British Columbia. Mar Mamm Sci 18:843-862

$>$ Otani S (2000) Diving behaviour and swimming speed of a free-ranging harbour porpoise, Phocoena phocoena. Mar Mamm Sci 16:811-814

Reid JB, Evans PGH, Northridge SP (2003) Atlas of Cetacean distribution in north-west European waters. Joint Nature Conservation Committee, Peterborough

Rendell LE, Gordon JCD (1999) Vocal response of long-finned pilot whales (Globicephala melas) to military sonar in the Ligurian Sea. Mar Mamm Sci 15:198-204

Richardson WJ, Greene CR, Malme CI, Thompson DH (1995) Marine Mammals and Noise. Academic Press, San Diego, CA

Siebert U, Rye JH (2008) Correlation between aerial surveys and acoustic monitoring. In: Wollny-Goerke, K. and K. Eskildsen (eds) Marine mammals and seabirds in front of offshore wind energy. Teubner, Wiesbaden

Simon M, Nuuttila H, Reyes-Zamudio MM, Ugarte F, Verfuß U, Evans PGH (2010) Passive acoustic monitoring of bottlenose dolphin and harbour porpoise in Cardigan Bay, Wales, with implications for habitat use and partitioning.

Editorial responsibility: Hans Heinrich Janssen, Oldendorf/Luhe, Germany
J Mar Biol Ass UK 90:1539-1545

Southall BL, Bowles AE, Ellison WT, Finneran JJ and others (2007) Marine Mammal Noise Exposure Criteria: Initial Scientific Recommendations. Aquat Mamm 33:411-414

Teilmann J, Tougaard J, Miller LA, Kirketerp T, Hansen K, Brando S (2006) Reactions of captive harbor porpoises (Phocoena phocoena) to pinger-like sounds. Mar Mamm Sci 22:240-260

Thiele \& Schellstede (1980) Standardwerte zur Ausbreitungsdämpfung in der Nordsee. FWG-Bericht 1980-7. Forschungsanstalt der Bundeswehr für Wasserschall und Geophysik, Kiel

Thompson PM, Lusseau D, Barton T, Simmons D, Rusin J, Bailey H (2010) Assessing the responses of coastal cetaceans to the construction of offshore wind turbines. Mar Pollut Bull 60:1200-1208

Thomsen F, van Elk N, Brock V, Piper W (2005) On the performance of automated porpoise-click-detectors in experiments with captive harbor porpoises (Phocoena phocoena). J Acoust Soc Am 118:37-40

Thomsen F, Lüdemann K, Kafemann R, Piper W (2006) Effects of offshore wind farm noise on marine mammals and fish. Biola, Hamburg, on behalf of COWRIE Ltd.

Tougaard J, Rosager Poulsen L, Amundin M, Larsen F, Rye J, Teilmann J (2006) Detection function of T-PODs and estimation of porpoise densities. In: Leeney RH, Tregenza NJC (eds) Proc Workshop Static Acoustic Monitoring of Cetaceans. 20th Annual Meeting of the European Cetacean Society, Gdynia, Poland 2 April 2006. ECS newsletter No. 46, Special Issue, p 7-9

- Tougaard J, Carstensen J, Teilmann J (2009) Pile driving zone of responsiveness extends beyond $20 \mathrm{~km}$ for harbour porpoises (Phocoena phocoena (L.)). J Acoust Soc Am 126: $11-14$

Tyack PL (2008) Implications for marine mammals of largescale changes in the marine acoustic environment. J Mammal 89:549-558

Verfuß UK, Honnef CG, Medling A, Dähne M, Mundry R, Benke H (2007) Geographical and seasonal variation of harbour porpoise (Phocoena phocoena) presence in the German Baltic Sea revealed by passive acoustic monitoring. J Mar Biol Assoc UK 87:165-176

Verfuß UK, Honnef CG, Medling A, Dähne M, Adler S, Kilian A, Benke H (2008) The history of the German Baltic Sea harbour porpoise acoustic monitoring at the German Oceanographic Museum. In: Wollny-Goerke, K. and K. Eskildsen (eds) Marine mammals and seabirds in front of offshore wind energy. Teubner, Wiesbaden

Weilgart LS (2007) The impacts of anthropogenic noise on cetaceans and implications for management. Can J Zool 85:1091-1116

Submitted: July 14, 2010; Accepted: October 21, 2010 Proofs received from author(s): January 3, 2011 